\title{
The prevalence and determinants of physical activity promotion by Australian chiropractors: A cross sectional study
}

\author{
Matthew Fernandez ${ }^{\mathrm{a}, \mathrm{b}, *}$, Craig Moore ${ }^{\mathrm{b}, \mathrm{c}}$, Andreas Eklund ${ }^{\mathrm{b}, \mathrm{d}}$, Michael Swain ${ }^{\mathrm{a}, \mathrm{b}}$, Katie de Luca ${ }^{\mathrm{a}, \mathrm{b}}$, \\ David Sibbritt ${ }^{c}$, Jon Adams ${ }^{c}$, Wenbo Peng ${ }^{c}$ \\ ${ }^{a}$ Department of Chiropractic, Faculty of Science and Engineering, Macquarie University, Sydney, Australia \\ ${ }^{\mathrm{b}}$ Chiropractic Academy for Research Leadership (CARL), Sydney, Australia \\ ${ }^{\mathrm{c}}$ Australian Research Centre in Complementary and Integrative Medicine (ARCCIM), University of Technology Sydney, Australia \\ ${ }^{\mathrm{d}}$ Unit of Intervention and Implementation Research for Worker Health, The Institute of Environmental Medicine, Karolinska Institute, Stockholm, Sweden
}

\section{A R T I C L E I N F O}

\section{Keywords:}

Physical activity

Exercise

Chiropractic

Chiropractor

Practice-based research network

\begin{abstract}
A B S T R A C T
Background: Approximately one in four adults do not meet the World Health Organisation physical activity recommendations. While health promotion (i.e., physical activity) is common within chiropractic settings, little is known about chiropractors discussing this public health issue with their patients. The aim of our study is to examine the prevalence and characteristics of Australian chiropractors who frequently discuss patient physical activity.

Methods: A national cross-sectional survey of chiropractors focusing upon practitioner characteristics, practice settings and clinical management characteristics. Regression analyses were conducted on 1924 survey respondents to identify factors associated with practitioners who frequently discuss physical activity with patients. Results: Eighty-five percent of Australian chiropractors reported 'often' discussing physical activity as part of their patient management. The strongest factors associated with chiropractors who frequently discuss physical activity obtained from the multivariate analysis include: often discussing occupational health and safety (odds ratio $[\mathrm{OR}]=6.10$; 95\%CI: 3.88, 9.59), often discussing diet/nutrition (OR $=4.56$; 95\%CI: 3.12, 6.66), often discussing smoking/drugs/alcohol (OR $=4.41$; 95\%CI: $2.06,9.40)$, often use of specific exercise therapy/rehabilitation/injury taping ( $\mathrm{OR}=3.76$; 95\%CI: 2.62, 5.39) and often caring for athletes or sports people $(\mathrm{OR}=2.18 ; 95 \% \mathrm{CI}: 1.56,3.06)$ within their practice setting.

Conclusion: Discussing physical activity is a frequent feature of patient management among most chiropractors in Australia. The association between these practitioners and discussion of other costly public health burdens could suggest chiropractors have a valuable role to play in chronic disease prevention. Given the growing need for practitioner-led promotion of patient physical activity further research examination of the role and contribution of chiropractors in promoting this important public health topic among patients and communities is needed.
\end{abstract}

\section{Background}

Physical inactivity is a major worldwide epidemic, associated with an increased risk of all-cause mortality. ${ }^{1,2}$ As the fourth leading modifiable cause of disease burden, ${ }^{3}$ physical inactivity is responsible for up to $10 \%$ of non-communicable diseases, including coronary heart disease, type 2 diabetes and a range of cancers. ${ }^{4}$ For chronic disease prevention, the World Health Organisation recommends $150 \mathrm{~min}$ of moderate-intensity physical activity per week, or 75 min per week of vigorous-intensity physical activity, as well as muscle strengthening activities twice per week. ${ }^{5}$ Despite the numerous health benefits associated with physical activity, these recommendations are not being met. In Australia for instance, health surveys point towards a decline in leisure time physical activity and a lack of improvement in inactivity

Abbreviations: ACORN, Australian Chiropractic Research Network; PBRN, practice-based research network; AHPRA, Australian Health Practitioner Regulation Agency

*Corresponding author at: Department of Chiropractic, Level 3, Room 369, 17 Wally's Walk, Macquarie University, NSW, 2109, Australia.

E-mail addresses: matthew.fernandez@mq.edu.au (M. Fernandez), craigsmoore@mac.com (C. Moore), andreas.eklund@ki.se (A. Eklund), michael.swain@mq.edu.au (M. Swain), katie.deluca@mq.edu.au (K. de Luca), david.sibbritt@uts.edu.au (D. Sibbritt), jon.adams@uts.edu.au (J. Adams), wenbo.peng@uts.edu.au (W. Peng). 
levels in the last two decades. ${ }^{6}$ Only $15 \%$ of Australian adults currently meet the full national physical activity guidelines that consist of moderate-to-vigorous activity five times per week and strength training twice per week. ${ }^{7-9}$ Further, only $7 \%$ of children are getting one hour of exercise per day. ${ }^{7}$

Physical activity uptake is an important public health goal in many countries. The World Health Organisation recognises the global impact of physical inactivity and has launched a worldwide plan to reduce it by $10 \%$ by 2025 and $15 \%$ by $2030 .{ }^{10}$ Health care providers can play an integral role in communicating this public health information in the patient care setting. ${ }^{11}$ The chiropractic profession represents a substantial component of the Australian allied health care system with chiropractors managing an estimated 21.3 million patient visits per year. ${ }^{12}$ While chiropractors are trained and educated in the diagnosis and management of a broad range of musculoskeletal conditions, ${ }^{13}$ they are also recognised as advocates for active lifestyle, general wellness and health promotion, ${ }^{12,14-16}$ with at least $90 \%$ prescribing or advising on physical activity or exercise in their consultations. ${ }^{12,14,17-20}$ People seeking chiropractic care for back complaints are also more likely to have poorer health and report several chronic diseases, ${ }^{21-23}$ compared to the general population. ${ }^{3}$

Evidence suggests the implementation of physical activity interventions has a favourable impact on pain severity, mental health, physical functioning ${ }^{24}$ and chronic diseases ${ }^{25}$ while at the same time is unlikely to cause any adverse effects. ${ }^{24}$ The chiropractic profession is well positioned in the community to promote physical activity, particularly for those people with musculoskeletal complaints. Yet, the role that these providers play in influencing such behaviour and lifestylerelated risk factors remains under researched. In direct response to this significant gap, this paper reports findings from a study examining the practitioner, practice and patient management characteristics of Australian chiropractors who regularly discuss physical activity with their patients.

\section{Methods}

\subsection{Sample}

This paper reports analyses from a workforce questionnaire distributed as part of the Australian Chiropractic Research Network (ACORN) project - a national voluntary chiropractic practice-based research network (PBRN) database. Details regarding the ACORN project recruitment, promotion strategy, and participants have been reported elsewhere, ${ }^{12,26,27}$ but briefly, 2005 practising chiropractors across Australia completed and returned the practitioner database questionaire between March and July 2015, representing a response rate of $43 \%$. The participating ACORN project sample has been shown to be generally representative of the wider Australian chiropractic profession in terms of age, gender, and practice location in comparison with the total population of chiropractors ${ }^{12}$ as registered by the Australian Health Practitioner Regulation Agency (AHPRA). ${ }^{28}$ The ACORN project was approved by the Human Research Ethics Committee of the University of Technology Sydney (\#2014000027).

\subsection{Questionnaire}

\subsubsection{Dependent variable: physical activity discussion}

This 21-item workforce questionnaire addresses three key areas of chiropractic practitioner characteristics, practice characteristics, and clinical management approaches. The participants were asked about how often they discuss physical activity with their patients via the question: "Indicate the frequency with which you discuss the following [physical activity] as part of your care/management plans" with the response options of "never", "rarely", "sometimes", and "often". The responses were recoded into two categories: discussing physical activity 'often' and 'not often' which included the original answer options 'never', 'rarely', and 'sometimes'.

\subsubsection{Independent variables: demographic and practice characteristics}

The questionnaire collected information regarding age, gender, highest professional qualifications, and working years in chiropractic private practice. The practice characteristics section collected data on average patient care hours and number of patient visits per week, practice location, other health professionals working in the same practice location, professional referral relationships, and the use of diagnostic imaging. In addition, participants were asked about their clinical management, including: discussion of other public health related topics (in addition to and distinct from physical activity) with their patients; frequency of treating patients amongst a range of patient subgroups and presenting with a range of conditions, and the use of a range of musculoskeletal interventions and other therapeutic techniques in their patient management.

\subsection{Statistical analyses}

Statistical analyses were conducted using the statistical software Stata 13.1. Bivariate logistic regression analysis was used to determine the associations of physical activity discussion with demographic and practice characteristics. A backward stepwise multivariate logistic regression was used to identify the most important independent predictors of chiropractors who 'often' discuss physical activity or fitness with their patients as part of their management plans. All variables associated with the use of physical activity or fitness advice in patient care via the initial bivariate analyses at a p-value of $\leq 0.25$ were entered into the regression model. ${ }^{29}$ Then during the stepwise process, if the corresponding cofficient of of a variable had a p-value $>0.05$, the variable was removed from the model. Both crude and adjusted odds ratio (OR) with $95 \%$ confidence interval $(95 \% \mathrm{CI})$ were estimated separately for each independent variable.

\section{Results}

Of the 1924 (96.0\%) chiropractors who responded to the question regarding the frequency with which they discussed physical activity with their patients, 1634 (84.9\%) chiropractors reported that they often discussed physical activity as part of their management plans.

Table 1 shows the practitioner characteristics of participating chiropractors who discuss physical activity as a part of their patient care via bivariate regression analyses. The mean (SD) age and the mean (SD)

Table 1

Practitioner characteristics of chiropractors who discuss physical activity as part of patient care.

\begin{tabular}{|c|c|c|c|c|c|}
\hline \multirow{2}{*}{$\begin{array}{l}\text { Independent } \\
\text { variable }\end{array}$} & \multicolumn{5}{|c|}{ Dependent variable } \\
\hline & $\begin{array}{l}\text { Not often } \\
n=290\end{array}$ & Often $n=1634$ & $\begin{array}{l}\text { Crude } \\
\text { Odds } \\
\text { Ratio }\end{array}$ & $95 \% \mathrm{CI}$ & $\mathrm{p}$ \\
\hline $\begin{array}{l}\text { Age in years } \\
\quad \text { mean } \pm s d\end{array}$ & $43.4 \pm 13.4$ & $42.0 \pm 11.8$ & 0.99 & $0.98-1.00$ & 0.065 \\
\hline Gender $n(\%)$ & & & 1.15 & $0.89-1.50$ & 0.285 \\
\hline Male & $189(65.2 \%)$ & $1006(61.9 \%)$ & & & \\
\hline Female & $101(34.8 \%)$ & $620(38.1 \%)$ & & & \\
\hline $\begin{array}{l}\text { Qualification } n \\
\quad(\%)\end{array}$ & & & 1.04 & $0.90-1.19$ & 0.339 \\
\hline Diploma & $11(3.8 \%)$ & $42(2.6 \%)$ & & & \\
\hline Bachelor & $94(32.6 \%)$ & $574(35.4 \%)$ & & & \\
\hline $\begin{array}{l}\text { Doctor of } \\
\text { Chiropractic }\end{array}$ & $95(33.0 \%)$ & $467(28.8 \%)$ & & & \\
\hline Master's degree & $87(30.2 \%)$ & $526(32.4 \%)$ & & & \\
\hline $\mathrm{PhD}$ & $1(0.4 \%)$ & $14(0.9 \%)$ & & & \\
\hline $\begin{array}{l}\text { Years in practice } \\
\text { mean } \pm s d\end{array}$ & $17.2 \pm 12.8$ & $15.6 \pm 11.0$ & 0.99 & $0.98-1.00$ & 0.037 \\
\hline
\end{tabular}


Table 2

Chiropractic practice characteristics regarding discussion about physical activity as part of patient care.

\begin{tabular}{|c|c|c|c|c|c|}
\hline \multirow[t]{2}{*}{ Independent variable } & \multicolumn{5}{|l|}{ Dependent variable } \\
\hline & Not often $n=290$ & Often $n=1634$ & Crude Odds Ratio & $95 \% \mathrm{CI}$ & $\mathrm{p}$ \\
\hline Patient care hours per week mean $\pm s d$ & $26.0 \pm 10.3$ & $27.7 \pm 16.5$ & 1.01 & $1.00-1.02$ & 0.085 \\
\hline Patient visits per week mean $\pm s d$ & $88.5 \pm 56.1$ & $87.3 \pm 57.8$ & 1.00 & $0.99-1.01$ & 0.752 \\
\hline Location $n(\%)$ & & & 1.54 & $1.16-2.05$ & 0.003 \\
\hline Urban & $185(69.0 \%)$ & $1194(77.4 \%)$ & & & \\
\hline Rural \& remote & $83(31.0 \%)$ & $348(22.6 \%)$ & & & \\
\hline One practice location only $n(\%)$ & $219(75.5 \%)$ & $1220(74.9 \%)$ & 1.03 & $0.77-1.38$ & 0.821 \\
\hline \multicolumn{6}{|c|}{ Other health professionals active in the practice location $n(\%)$} \\
\hline General practitioner & $26(9.0 \%)$ & $96(5.9 \%)$ & 0.63 & $0.40-1.00$ & 0.048 \\
\hline Psychologist/counsellor & $39(13.5 \%)$ & $200(12.2 \%)$ & 0.90 & $0.62-1.30$ & 0.565 \\
\hline Physiotherapist & $30(10.3 \%)$ & $148(9.1 \%)$ & 0.86 & $0.57-1.31$ & 0.486 \\
\hline Occupational therapist & $8(2.8 \%)$ & $40(2.5 \%)$ & 0.88 & $0.41-1.91$ & 0.755 \\
\hline Podiatrist & $27(9.3 \%)$ & $153(9.4 \%)$ & 1.01 & $0.65-1.55$ & 0.977 \\
\hline Medical specialist & $11(3.8 \%)$ & $411(2.5 \%)$ & 0.65 & $0.33-1.29$ & 0.217 \\
\hline Exercise physiologist & $13(4.5 \%)$ & $112(6.9 \%)$ & 1.57 & $0.87-2.82$ & 0.134 \\
\hline Another chiropractor & $137(47.2 \%)$ & $983(60.2 \%)$ & 1.69 & $1.31-2.17$ & $<0.001$ \\
\hline \multicolumn{6}{|l|}{ Referral relationships $n(\%)$} \\
\hline General practitioner & $134(46.2 \%)$ & $958(58.6 \%)$ & 1.65 & $1.28-2.12$ & $<0.001$ \\
\hline Psychologist/counsellor & $25(8.6 \%)$ & $250(15.3 \%)$ & 1.91 & $1.24-2.95$ & 0.003 \\
\hline Physiotherapist & $67(23.1 \%)$ & $541(33.1 \%)$ & 1.65 & $1.23-2.21$ & 0.001 \\
\hline Occupational therapist & $18(6.2 \%)$ & $143(8.8 \%)$ & 1.45 & $0.87-2.41$ & 0.151 \\
\hline Podiatrist & $79(27.2 \%)$ & $682(41.7 \%)$ & 1.91 & $1.45-2.52$ & $<0.001$ \\
\hline Medical specialist & $29(10.0 \%)$ & $279(17.1 \%)$ & 1.85 & $1.24-2.78$ & 0.003 \\
\hline Exercise physiologist & $21(7.2 \%)$ & $279(17.1 \%)$ & 2.64 & $1.66-4.19$ & $<0.001$ \\
\hline None & $82(28.3 \%)$ & $321(19.7 \%)$ & 0.62 & $0.47-0.82$ & 0.001 \\
\hline Using imaging (used often) $n(\%)$ & $119(41.3 \%)$ & $791(48.7 \%)$ & 1.35 & $1.04-1.73$ & 0.022 \\
\hline \multicolumn{6}{|c|}{ Treating the following patient subgroups (treated often) $n(\%)$} \\
\hline Older people (65 years or over) & $193(70.2 \%)$ & $1197(74.0 \%)$ & 1.21 & $0.91-1.60$ & 0.182 \\
\hline Aboriginal and Torres Strait Islander people & $4(1.5 \%)$ & $29(1.8 \%)$ & 1.25 & $0.44-3.60$ & 0.673 \\
\hline Pregnant women & $74(26.9 \%)$ & $619(38.4 \%)$ & 1.70 & $1.27-2.25$ & $<0.001$ \\
\hline Athletes or sports people & $71(25.9 \%)$ & $859(53.5 \%)$ & 3.29 & $2.47-4.38$ & $<0.001$ \\
\hline People with work-related injuries & $64(23.7 \%)$ & $606(38.4 \%)$ & 2.01 & $1.49-2.70$ & $<0.001$ \\
\hline People with traffic-related injuries & $25(9.2 \%)$ & $227(14.4 \%)$ & 1.65 & $1.07-2.56$ & 0.023 \\
\hline People receiving post-surgical rehabilitation & $9(3.3 \%)$ & $110(7.0 \%)$ & 2.19 & $1.10-4.37$ & 0.026 \\
\hline Non-English-speaking ethnic groups & $16(6.1 \%)$ & $101(6.6 \%)$ & 1.09 & $0.63-1.88$ & 0.756 \\
\hline
\end{tabular}

working years in chiropractic practice of chiropractors who often discuss physical activity with patients were 42.0 (11.8) years and 15.6 (11.0) years, respectively. Amongst these chiropractors, $61.9 \%$ were male and $32.4 \%$ had Master's degree in chiropractic. Chiropractors who often discuss physical activity with patients were more likely to have less working years in private chiropractic practice than those who do not often discuss activity with their patients $(\mathrm{p}=0.04)$. However, age, gender, and qualification of chiropractors were not statistically significantly associated with their frequency of physical activity discussion with patients.

The practice characteristics of participating chiropractors who discuss physical activity as part of patient care via bivariate regression analyses are shown in Table 2. Chiropractors practicing in urban locations were more likely to often discuss physical activity with patients (crude OR $=1.54$; 95\%CI: 1.16, 2.05; $\mathrm{p}=0.003$ ). Chiropractors often using diagnostic imaging were more likely to often discuss physical activity with patients (crude OR $=1.35$; 95\%CI: 1.04, 1.73; $\mathrm{p}=0.022$ ). Chiropractors who work alongside another chiropractor at their practice location were more likely to often discuss physical activity with patients (crude OR = 1.69; 95\%CI: 1.31, 2.17; p < 0.001), while those who work with a general practitioner (GP) at their practice location were less likely to often discuss physical activity with patients (crude $\mathrm{OR}=0.63$; 95\%CI: 0.40, 1.00; $\mathrm{p}=0.048$ ). Chiropractors who often discuss physical activity with patients were more likely to have referral relationship with other health professionals. Specifically, chiropractors who have referral relationships with a GP, a psychologist/counsellor, a physiotherapist, a podiatrist, a medical specialist, and/or an exercise physiologist were significantly associated with frequent physical activity discussions in patient care (crude OR range: 1.45-2.64; all $\mathrm{p}<0.005$ ). In addition, chiropractors who often treat pregnant women, athletes/sports people, people with work-related and trafficrelated injuries, and/or people receiving post-surgical rehabilitation were significantly associated with frequent physical activity discussions in patient care (crude OR range: 1.65-3.29; all $\mathrm{p}<0.05$ ).

With regards to clinical management (Table 3 ), in the univariate analysis, chiropractors who often discuss physical activity with patients were also more likely to often discuss diet/nutrition (crude $\mathrm{OR}=6.30$; 95\% CI: 4.56, 8.70), smoking/drugs/alcohol (crude OR $=13.81 ; 95 \%$ CI: $6.78,28.11$ ), occupational health and safety (crude OR $=8.24 ; 95 \%$ CI: $5.48,12.39$ ), pain counselling (crude $\mathrm{OR}=3.97 ; 95 \%$ CI: 2.57 , 6.11), nutritional supplements (crude OR $=3.03$; 95\% CI: $2.21,4.14$ ), and/or medications with patients (crude OR $=3.26$; $95 \% \mathrm{CI}$ : 2.16 , 4.93) (all $\mathrm{p}<0.001$ ). There was statistical differences between chiropractors who often and not often discuss physical activity with patients regarding the frequently delivered treatment of axial (crude $\mathrm{OR}=3.59 ; \quad 95 \% \quad \mathrm{CI}: 2.41,5.34$ ) or referred/radicular (crude $\mathrm{OR}=1.65 ; 95 \%$ CI: $1.28,2.13$ ) neck pain, axial thoracic pain (crude $\mathrm{OR}=2.35 ; 95 \%$ CI: $1.73,3.18$ ), axial (crude OR $=3.82 ; 95 \%$ CI: 2.50 , 5.84) or referred/radicular (crude OR $=1.90 ; 95 \%$ CI: $1.42,2.54$ ) back pain, lower (crude OR $=1.96 ; 95 \%$ CI: $1.52,2.54$ ) or upper (crude $\mathrm{OR}=2.10 ; 95 \% \mathrm{CI}: 1.63,2.72) \mathrm{limb}$ musculoskeletal conditions, postural disorders (crude $\mathrm{OR}=2.82$; 95\% CI: $2.17,3.68$ ), degenerative spine conditions (crude OR $=2.19 ; 95 \%$ CI: $1.68,2.84$ ), headache (crude OR $=2.21 ; 95 \% \mathrm{CI}: 1.60,3.07$ ), or spinal health maintenance/ prevention (crude OR $=1.81 ; 95 \%$ CI: $1.38,2.38$ ) (all $\mathrm{p}<0.001$ ). The frequent use of chiropractic techniques such as high velocity low amplitude manipulation (crude OR $=1.73$; 95\% CI: $1.28,2.34$ ), extremity manipulation (crude OR $=1.86 ; 95 \%$ CI: $1.44,2.41$ ), soft tissue therapy (crude OR $=1.87 ; 95 \%$ CI: $1.44,2.42$ ), or specific exercise therapy/ rehabilitation/injury taping (crude $\mathrm{OR}=4.74 ; 95 \%$ CI: $3.47,6.47$ ) 
Table 3

Clinical management regarding discussion about physical activity as part of patient care.

\begin{tabular}{|c|c|c|c|c|c|}
\hline \multirow[t]{2}{*}{ Independent variable } & \multicolumn{5}{|l|}{ Dependent variable } \\
\hline & Not often $n=290$ & Often $n=1634$ & Crude Odds Ratio & $95 \% \mathrm{CI}$ & $\mathrm{p}$ \\
\hline \multicolumn{6}{|l|}{ Discussed as part of the care/management plan (done often) $n(\%)$} \\
\hline Diet/nutrition & $49(17.1 \%)$ & $921(56.5 \%)$ & 6.30 & 4.56-8.70 & $<0.001$ \\
\hline Smoking/drugs/alcohol & $8(2.8 \%)$ & $465(28.6 \%)$ & 13.81 & $6.78-28.11$ & $<0.001$ \\
\hline Occupational health and safety & $27(9.5 \%)$ & $755(46.5 \%)$ & 8.24 & $5.48-12.39$ & $<0.001$ \\
\hline Pain counselling & $24(8.7 \%)$ & $442(27.3 \%)$ & 3.97 & $2.57-6.11$ & $<0.001$ \\
\hline Nutritional supplements & $53(18.3 \%)$ & $659(40.5 \%)$ & 3.03 & $2.21-4.14$ & $<0.001$ \\
\hline Medications & $27(9.5 \%)$ & $414(25.6 \%)$ & 3.26 & $2.16-4.93$ & $<0.001$ \\
\hline \multicolumn{6}{|l|}{ Treating patients with the following conditions (done often) $n$ (\%) } \\
\hline Neck pain (axial) & $237(84.6 \%)$ & $1543(95.2 \%)$ & 3.59 & $2.41-5.34$ & $<0.001$ \\
\hline Neck pain (referred/radicular) & $147(52.5 \%)$ & $1048(64.6 \%)$ & 1.65 & $1.28-2.13$ & $<0.001$ \\
\hline Thoracic pain (axial) & $202(73.5 \%)$ & $1402(86.7 \%)$ & 2.35 & $1.73-3.18$ & $<0.001$ \\
\hline Thoracic pain (referred/radicular) & $115(41.8 \%)$ & $760(47.3 \%)$ & 1.25 & $0.96-1.62$ & 0.093 \\
\hline Low back pain (axial) & $241(86.4 \%)$ & $1552(96.0 \%)$ & 3.82 & $2.50-5.84$ & $<0.001$ \\
\hline Low back pain (referred/radicular) & $199(71.3 \%)$ & $1335(82.6 \%)$ & 1.90 & $1.42-2.54$ & $<0.001$ \\
\hline Lower limb musculoskeletal disorders & $129(46.2 \%)$ & $1017(62.8 \%)$ & 1.96 & $1.52-2.54$ & $<0.001$ \\
\hline Upper limb musculoskeletal disorders & $131(47.1 \%)$ & $1053(65.2 \%)$ & 2.10 & $1.63-2.72$ & $<0.001$ \\
\hline Postural disorders & $108(39.7 \%)$ & $1028(65.0 \%)$ & 2.82 & $2.17-3.68$ & $<0.001$ \\
\hline Degenerative spine conditions & $132(48.7 \%)$ & $1067(67.5 \%)$ & 2.19 & $1.68-2.84$ & $<0.001$ \\
\hline Headache disorders & $213(78.0 \%)$ & $1406(88.7 \%)$ & 2.21 & $1.60-3.07$ & $<0.001$ \\
\hline Migraine disorders & $123(45.1 \%)$ & $861(54.3 \%)$ & 1.45 & $1.12-1.88$ & 0.005 \\
\hline Spinal health maintenance/prevention & $169(62.4 \%)$ & $1187(75.0 \%)$ & 1.81 & $1.38-2.38$ & $<0.001$ \\
\hline Non-musculoskeletal disorders & $51(25.8 \%)$ & $357(30.5 \%)$ & 1.27 & $0.90-1.78$ & 0.175 \\
\hline \multicolumn{6}{|l|}{ Using the following techniques/methods (used often) $n$ (\%) } \\
\hline Drop-piece techniques/Thompson or similar & $139(50.7 \%)$ & $868(54.3 \%)$ & 1.15 & 0.89-1.49 & 0.276 \\
\hline Biomechanical pelvic blocking/Sacro-Occipital technique & $94(34.7 \%)$ & $728(45.6 \%)$ & 1.58 & $1.20-2.06$ & 0.001 \\
\hline Instrument adjusting & $129(46.9 \%)$ & $851(53.1 \%)$ & 1.28 & $0.99-1.66$ & 0.058 \\
\hline Chiropractic biophysics & $16(6.2 \%)$ & $60(3.9 \%)$ & 0.63 & $0.35-1.10$ & 0.105 \\
\hline High velocity low amplitude adjustment/manipulation & $205(74.8 \%)$ & $1344(83.7 \%)$ & 1.73 & $1.28-2.34$ & $<0.001$ \\
\hline Applied kinesiology & $51(18.9 \%)$ & $246(15.6 \%)$ & 0.79 & $0.57-1.11$ & 0.176 \\
\hline Flexion-distraction & $17(6.3 \%)$ & $128(8.2 \%)$ & 1.31 & $0.78-2.22$ & 0.309 \\
\hline Functional neurology & $24(9.1 \%)$ & $216(13.9 \%)$ & 1.61 & $1.03-2.51$ & 0.035 \\
\hline Extremity manipulation & $125(45.8 \%)$ & $981(61.2 \%)$ & 1.86 & $1.44-2.41$ & $<0.001$ \\
\hline \multicolumn{6}{|l|}{ Musculoskeletal interventions (used often) $n(\%)$} \\
\hline Dry needling/acupuncture & $20(7.3 \%)$ & $238(14.9 \%)$ & 2.21 & $1.37-3.55$ & 0.001 \\
\hline Soft tissue therapy, trigger point therapy, massage therapy & $148(53.6 \%)$ & $1103(68.3 \%)$ & 1.87 & $1.44-2.42$ & $<0.001$ \\
\hline Electro-modalities & $17(6.2 \%)$ & $165(10.3 \%)$ & 1.75 & $1.05-2.94$ & 0.033 \\
\hline Heat/cryotherapy & $27(9.9 \%)$ & $285(17.8 \%)$ & 1.99 & $1.31-3.01$ & 0.001 \\
\hline Orthotics & $21(7.7 \%)$ & $167(10.4 \%)$ & 1.40 & $0.87-2.25$ & 0.164 \\
\hline Specific exercise therapy/rehabilitation/injury taping & $55(20.1 \%)$ & $867(54.3 \%)$ & 4.74 & $3.47-6.47$ & $<0.001$ \\
\hline
\end{tabular}

were significantly associated with the frequent physical activity discussion with chiropractic patients (all $\mathrm{p}<0.001$ ).

A total of 56 variables were initially entered into the multivariate model and seven variables were included in the final multivariate model. Multivariable logistic regression analyses identified seven factors that were independently associated with the likelihood of a chiropractor often discussing physical activity as part of patient care (Table 4). Such factors included frequently discussing occupational health and safety (adjusted OR $=6.10$; 95\%CI: 3.88, 9.59, $\mathrm{p}<0.001$ ); diet/nutrition (adjusted OR $=4.56$; 95\%CI: 3.12, 6.66, $\mathrm{p}<0.001$ ) and smoking/drugs/alcohol (adjusted $\mathrm{OR}=4.41 ; 95 \% \mathrm{CI}$ : 2.06, 9.40, $\mathrm{p}<0.001$ ). Other factors included frequently using specific exercise therapy/rehabilitation/injury taping (adjusted OR $=3.76$; 95\%CI: $2.62,5.39, \mathrm{p}<0.001$ ); frequently treating athletes or sports people (adjusted OR $=2.18$; 95\%CI: 1.56, 3.06, $\mathrm{p}<0.001$ ) and frequently treating spinal health maintenance/prevention (adjusted $\mathrm{OR}=1.43$; $95 \%$ CI: $1.03,1.99, \mathrm{p}=0.034)$. However, the lack of referral relationship with other health care practitioners was negatively associated with often discussing physical activity with patients (adjusted $\mathrm{OR}=0.57$; 95\%CI: $0.40,0.82, \mathrm{p}=0.002$ ).

\section{Discussion}

Drawing upon a national representative sample, our study highlights a significant number of public health issues related to everyday chiropractic consultation. Notably, 5 out of every 6 Australian chiropractors incorporate physical activity discussions as part of their clinical management.

Our study found chiropractors who often discuss physical activity are more likely to often discuss occupational health and safety as part of

Table 4

Factors associated with chiropractors who frequently discuss physical activity as part of patient care.

\begin{tabular}{|c|c|c|c|}
\hline Variable & Adjusted Odds ratio & $95 \% \mathrm{CI}$ & $\mathrm{p}$ \\
\hline Discussing occupational health and safety with patients (often) & 6.10 & 3.88-9.59 & $<0.001$ \\
\hline Discussing diet/nutrition with patients (often) & 4.56 & $3.12-6.66$ & $<0.001$ \\
\hline Discussing smoking/drugs/alcohol with patients (often) & 4.41 & $2.06-9.40$ & $<0.001$ \\
\hline Using specific exercise therapy/rehabilitation/injury taping (often) & 3.76 & $2.62-5.39$ & $<0.001$ \\
\hline Treating athletes or sports people (often) & 2.18 & $1.56-3.06$ & $<0.001$ \\
\hline Treating spinal health maintenance/prevention (often) & 1.43 & 1.03-1.99 & 0.034 \\
\hline No professional referral relationship with other practitioners & 0.57 & $0.40-0.82$ & 0.002 \\
\hline
\end{tabular}


their patient care than those who do not often discuss physical activity. Engagement in physical activity has known protective effects on workrelated musculoskeletal injuries. ${ }^{30}$ However, an increasing proportion of the workforce have occupations that are sedentary, i.e., sitting ${ }^{31}$ and coupled with low levels of physical activity, is associated with poor health, productivity losses, job dissatisfaction, absence and high turnover. ${ }^{32}$ As such, it is not too surprising that almost half of the chiropractors surveyed in our study were likely to discuss physical activity and occupational health and safety. Previous literature suggests chiropractors promote safe work environments by conducting worksite assessments ${ }^{33}$ and knowingly discuss workplace injury and ergonomic stress on occupational 'at-risk' patients. ${ }^{14,20}$ However a discussion on the increased sitting habits in the work setting ${ }^{34}$ - now the largest contributors to daily sedentary time in workers ${ }^{35}$ - is unknown. Further, whether chiropractors discuss and prescribe specific exercises (i.e., strengthening activities) as part of their physical activity promotion in the workplace is yet to be determined. Given that prolonged sitting is associated with an increased risk of various chronic diseases and premature mortality, ${ }^{36}$ the workplace is a key environment to discuss physical activity alongside occupational health and safety, and should be further investigated.

Our study found chiropractors who often discuss physical activity are also more likely to often discuss diet/nutrition as part of their patient management. One reason for these shared discussions may relate to the relationship between physical activity and nutrition, with those who are physical inactive generally more likely to adopt poor nutritional habits. ${ }^{37}$ For instance, sedentary activity such as watching television has been shown to overlap with the consumption of excessive, unhealthy foods in both youth ${ }^{38}$ and adults. ${ }^{39}$ In Australia, few adults meet the fruit and vegetable intake guidelines, ${ }^{40}$ with a dominance of excessive calorie dense, ultra-processed food intake, posing a risk for heart disease, type 2 diabetes ${ }^{3}$ and several cancers. ${ }^{41}$ Approximately $55 \%$ of chiropractors discussed diet/nutrition in relation to physical activity in our study, however the nature of these discussions was not explored. While recent evidence suggests chiropractic diet/nutrition advice likely relates to nutritional supplement intake, ${ }^{42}$ it is possible that our findings may relate to previous Australian literature, which suggests that a high percentage of chiropractors prefer health information brochures (such as information on nutritional supplements) over direct one-on-one diet/nutrition consultation. ${ }^{43}$ Increased work demands and unpaid time required to pursue in-depth diet/nutrition therapy or counselling by chiropractors are possible reasons for this form of consultation. ${ }^{43,44}$ It maybe that Australian chiropractors in our study also lack the time and/or knowledge of nutritional guideline advice and may simply refer to dietary professionals. This issue should be clarified with further investigation.

In our study, discussing smoking/drugs/alcohol frequently was another factor independently associated with chiropractors often discussing physical activity with patients. ${ }^{42}$ Poor patient health behaviors seemingly cluster together, with physical inactivity adversely influencing the addictive process associated with alcohol consumption, tobacco smoking and substance abuse. ${ }^{45}$ Yet, physical activity participation has shown a reduction in the desire for substance abuse, cravings as well as withdrawal symptoms and relapse episodes, over an extended period of time. ${ }^{46-48}$ Despite being modifiable lifestyle behavioural risk factors, less than $30 \%$ of chiropractors in our study discussed smoking/ drugs/alcohol in relation to physical activity. While the reasons in our study were not clear, our findings are in line with a previous Australian study which showed only a small percentage of chiropractors offer information or education on smoking cessation (35\%), alcohol (13\%) and substance abuse (12\%). ${ }^{43}$ Possible reasons for this include chiropractors being neutral or opposed to the discussion of adverse health behaviours due to experiences of unwanted patient responses and/or the lack of time during consultation to address these lifestyle behavioural issues. ${ }^{18}$ Another study showed chiropractors were willing to discuss lifestyle issues should the patient present with a lifestyle-related problem. ${ }^{19}$ It is plausible that chiropractors in our study may lack adequate education or training and therefore knowledge relating to substance abuse issues. Such issues should be explored in more depth in future studies.

Treating athletes/sports people frequently was significantly associated with chiropractors who often discuss physical activity with patients in our study. This finding is not surprising, given that sport is one part of physical activity participation and chiropractors are among a wide range of health professionals, who treat athletes or sports people. $^{49,50}$ Sports injuries pose a substantial health burden ${ }^{51,52}$ and constitute a common cause of pain and disability that can negatively impact an individual's quality of life and well-being. While physical activity is important to mitigate the risk of chronic disease and regular sports participation is likely to provide health benefits, it is also necessary to discuss physical activity in the context of a gradual return to sport, following sports injury for athletes and sports people. ${ }^{53}$ There are both advantages (i.e., physical adaptation) and disadvantages (i.e., injury risk) associated with physical training loads on fitness. ${ }^{54}$ In the event of injury, the decision to return to sport can be complex, requiring an individualised approach based on the athletes' circumstances. ${ }^{55}$ Sports injury management is common among Australian chiropractors, with almost $50 \%$ frequently treating athletes or sports people. ${ }^{50} \mathrm{Al}-$ though the relationship between physical activity and treating athletes/ sports people is conceivable, i.e., physical activity can effectively reduce sports and overuse injuries, ${ }^{56}$ it is also important to ensure the athlete's functional limits and milestones are agreed upon and honoured in the rehabilitation of musculoskeletal injuries. The reasons behind the relationship between physical activity and treating athletes/ sports people was not investigated in our study and warrant further research attention.

We found chiropractors who often discuss physical activity with patients were also more likely to often use specific exercise therapy/ rehabilitation/injury taping. This is not an unexpected finding, given chiropractors who utilise a multimodal approach to care (i.e., the combination of manipulative therapy with exercise prescription, strengthening, stretching, soft tissue therapy, active care programs and other ancillary therapies such as proprioception training) are also more likely to promote physical activity. ${ }^{49}$ The discussion of physical activity regarding specific exercise therapy/rehabilitation/injury taping may simply be linked to its preventative benefits, ${ }^{56}$ along with an end goal of rehabilitation that is aimed to restore functional limitations. Finally, the possibility remains that adjunctive techniques like taping are collinearly linked to physical activity discussion in the treatment of sports people, given adjunct techniques have a therapeutic effect on the management of sports related disorders. ${ }^{57,58}$

While our ACORN analysis draws upon a large nationally-representative sample of Australian chiropractors, drawing strong conclusions from our research may be limited. Our study is a secondary analysis and being cross-sectional in nature, it relies on the retrospective recall of practitioners. Also, our high-quality baseline data focused on broad issues around the chiropractic workforce and was not specifically designed to provide an in-depth analyses, i.e., knowledge, education or promotion of physical activity among Australian chiropractors. Our clinical management variable included the discussion of physical activity and fitness rather than just physical activity alone, potentially over-estimated physical activity discussions by including fitness as well. Despite these limitations, our study does examine the practitioner, practice and patient management characteristics of chiropractors who regularly discuss physical activity. Our results can assist in generating hypotheses to further explore (in subsequent sub studies) what recommendations are made by chiropractors as well as their knowledge of the Australian physical activity guidelines, by assessing the delivery of physical activity educational content within the chiropractic curricula and post graduate training. For example, our data was not able to elicit information on the Australian chiropractic curriculum with respect to physical activity education, however almost $50 \%$ of Australian and New Zealand chiropractic students recently surveyed 
only agree (vs. 25\% who strongly agree) with physical inactivity screening in the chiropractic setting. ${ }^{59}$ This seems to contrast practice reality, with $85 \%$ Australian chiropractors often discuss physical activity in clinical practice, suggesting there may be greater room for improvement within the student curriculum. For practitioners, greater impact may be achieved by developing an accessible physical activity framework, which includes contemporary knowledge on guideline recommendations, thus encouraging further active promotion within the chiropractic setting. ${ }^{60}$

\section{Conclusion}

Discussing physical activity is a frequent feature of patient management reported by a majority of chiropractors in Australia. Given the significance of physical activity for targeting the rising burden of noncommunicable disease, the potential of practitioner-led promotion for such behaviour change and the prevalence of chiropractic care amongst the Australian population, it is important future research further examine and evaluate the role and contribution of chiropractors in promoting this important public health topic amongst patients and communities.

\section{Ethics approval and consent to participate}

This is a secondary analysis of existing ACORN data (written consent was obtained by completing the existing ACORN survey). The ethics approval number for the ACORN data collection was approved by the Human Ethics Committee, University of Technology Sydney (\#2014000027).

\section{Funding}

The ACORN project is funded by the Australian Chiropractors Association of (ACA) and the authors are grateful their financial support for the ACORN PBRN.

\section{Authors' contributions}

MF, CM, MS, KDL, AE and JA initiated and designed the study protocol. WP, DS and JA undertook the data analysis and interpretation. All authors were responsible for reviewing and redrafting the final version of the manuscript. All authors read and approved the final manuscript.

\section{Availability of data and materials}

The datasets used and/or analyzed during the current study are available from co-author Jon Adams (UTS) on reasonable request.

\section{Consent for publication}

Not applicable.

\section{Acknowledgements}

The authors wish to acknowledge and thank the Australian chiropractors who participated in this study. Finally, the authors are solely responsible for the research reported in this paper and the CAA has no influence over the study design or analyses presented in this manuscript.

\section{References}

1. Arem H, Moore SC, Patel A, et al. Leisure time physical activity and mortality: a detailed pooled analysis of the dose-response relationship. JAMA Intern Med. 2015;175(6):959-967
2. Lahti J, Holstila A, Lahelma E, Rahkonen O. Leisure-time physical activity and allcause mortality. PLoS One. 2014;9(7):e101548.

3. AIHW. Australia's health 2016. Australia's health no. 15. Cat. No. AUS 199. Canberra: AIHW; 2016

4. Lee IM, Shiroma EJ, Lobelo F, Puska P, Blair SN, Katzmarzyk PT. Effect of physical inactivity on major non-communicable diseases worldwide: an analysis of burden of disease and life expectancy. Lancet. 2012;380(9838):219-229.

5. World Health Organization. Global recommendations on physical activity for health. Geneva, Switzerland: WHO; 2010.

6. Chau J, Chey T, Burks-Young S, Engelen L, Bauman A. Trends in prevalence of leisure time physical activity and inactivity: results from Australian National Health Surveys 1989 to 2011. Aust N Z J Public Health. 2017 n/a-n/a.

7. National Physical Activity Plan. Survey findings. 2016; 2016 (Accessed 22 August 2017). https://www.heartfoundation.org.au/.

8. Australia's physical activity and sedentary behaviour guidelines (adults). 2019; 2019http://www.health.gov.au/internet/main/publishing.nsf/Content/pasb.

9. Bennie JA, Pedisic Z, van Uffelen JG, et al. The descriptive epidemiology of total physical activity, muscle-strengthening exercises and sedentary behaviour among Australian adults-results from the National Nutrition and Physical Activity Survey. BMC Public Health. 2015;16(1):73.

10. WHO. The global action plan on physical activity 2018-2030. 2018; 2018 (Accessed 9 September 2018). http://www.who.int/ncds/prevention/physical-activity/gappa/ action-plan.

11. Lobelo F, de Quevedo IG. The evidence in support of physicians and health care providers as physical activity role models. Am J Lifestyle Med. 2016;10(1):36-52.

12. Adams J, Lauche R, Peng W, et al. A workforce survey of Australian chiropractic: the profile and practice features of a nationally representative sample of 2,005 chiropractors. BMC Complement Altern Med. 2017;17(1):14.

13. Chiropractic Accreditation and Competency Standards. Council on Chiropractic Education Australasia. 2017; 2017 Avaialble at: http://www.chiropracticboard.gov.au/ Accreditation.aspx (Accessed 4 September 2017).

14. Hawk C, Long CR, Perillo M, Boulanger KT. A survey of US chiropractors on clinical preventive services. J Manipulative Physiol Ther. 2004;27(5):287-298.

15. French SD, Charity MJ, Forsdike K, et al. Chiropractic Observation and Analysis Study (COAST): providing an understanding of current chiropractic practice. Med $J$ Aust. 2013;199(10):687-691.

16. Adams J, Peng W, Cramer H, et al. The prevalence, patterns, and predictors of chiropractic use among US adults: results from the 2012 National Health Interview Survey. Spine. 2017;42(23):1810-1816.

17. Hawk C, Schneider M, Evans MW, Redwood D. Consensus process to develop a best practice document on the role of chiropractic care in health promotion, disease prevention, and wellness. J Manipulative Physiol Ther. 2012;35(7):556-567.

18. Leach RA, Cossman RE, Yates JM. Familiarity with and advocacy of healthy people 2010 goals by Mississippi Chiropractic Association Members. J Manipulative Physiol Ther. 2011;34(6):394-406.

19. Fikar PE, Edlund KA, Newell D. Current preventative and health promotional care offered to patients by chiropractors in the United Kingdom: a survey. Chiropr Man Therap. 2015;23(1):10.

20. Christensen M, Hyland J, Goertz C, Kollasch M. Practice Analysis of Chiropractic 2015. A project report, survey analysis, and summary of chiropractic practice in the United States. Greeley Colorado: National Board of Chiropractic Examiners; 2015.

21. Fernandez M, Ordoñana JR, Hartvigsen J, et al. Is chronic low back pain associated with the prevalence of coronary heart disease when genetic susceptibility is considered? A co-twin control study of Spanish twins. PLoS One. 2016;11(5). e0155194 p. Available from: [Internet]. 2016 http://europepmc.org/abstract/MED/27171210 http://europepmc.org/articles/PMC4865187?pdf = render http://europepmc.org/ articles/PMC4865187 https://doi.org/10.1371/journal.pone.0155194.

22. Dario A, Ferreira M, Refshauge K, et al. Mapping the association between back pain and type 2 diabetes: a cross-sectional and longitudinal study of adult Spanish twins. PLoS One. 2017;12(4):e0174757.

23. Fernandez M, Colodro-Conde L, Hartvigsen J, et al. Chronic low back pain and the risk of depression or anxiety symptoms: insights from a longitudinal twin study. Spine J. 2017;17(7):905-912.

24. Geneen LJ, Moore RA, Clarke C, Martin D, Colvin LA, Smith BH. Physical activity and exercise for chronic pain in adults: an overview of cochrane reviews. Cochrane Database Syst Rev. 2017;4.

25. Pedersen BK, Saltin B. Exercise as medicine - evidence for prescribing exercise as therapy in 26 different chronic diseases. Scand J Med Sci Sports. 2015;25:1-72.

26. Adams J, Steel A, Moore C, Amorin-Woods L, Sibbritt D. Establishing the ACORN national practitioner database: strategies to recruit practitioners to a national Practice-Based Research Network. J Manipulative Physiol Ther. 2016;39(8):594-602.

27. Adams J, Peng W, Steel A, et al. A cross-sectional examination of the profile of chiropractors recruited to the Australian Chiropractic Research Network (ACORN): a sustainable resource for future chiropractic research. BMJ Open. 2017;7(9).

28. Chiropractic board of australia. Codes and guidelines; 2016 (Accessed 16 March 2018). http://www.chiropracticboard.gov.au/Codes-guidelines.aspx.

29. Hosmer David W, Stanley L. Applied logistic regression. 2nd ed. New York: John Wiley \& Sons, Inc.; 2000

30. Miranda H, Viikari-Juntura E, Martikainen R, Takala E, Riihimäki H. A prospective study of work related factors and physical exercise as predictors of shoulder pain Occup Environ Med. 2001;58(8):528-534.

31. Chau JY, van der Ploeg HP, Merom D, Chey T, Bauman AE. Cross-sectional associations between occupational and leisure-time sitting, physical activity and obesity in working adults. Prev Med. 2012;54(3-4):195-200.

32. Brown HE, Ryde GC, Gilson ND, Burton NW, Brown WJ. Objectively measured sedentary behavior and physical activity in office employees: relationships with 
presenteeism. J Occup Environ Med. 2013;55(8):945-953

33. Tuchin PJ, Bonello RP. Requirements for chiropractors involved as occupational health and safety consultants in Australia. Australas Chiropr Osteopathy. 1997;6(1):10.

34. Tanamas SKMD, Lynch B, Sethi P, et al. The Australian diabetes, obesity and lifestyle study. Melbourne: Baker IDI Heart and Diabetes Institute; 2012:2013.

35. Neuhaus M, Eakin EG, Straker L, et al. Reducing occupational sedentary time: a systematic review and meta-analysis of evidence on activity-permissive workstations. Obes Rev. 2014;15(10):822-838.

36. Mackenzie K, Such E, Norman P, Goyder E. The development, implementation and evaluation of interventions to reduce workplace sitting: a qualitative systematic review and evidence-based operational framework. BMC Public Health. 2018;18(1):833.

37. Gillman MW, Pinto BM, Tennstedt S, Glanz K, Marcus B, Friedman RH. Relationships of physical activity with dietary behaviors among adults. Prev Med. 2001;32(3):295-301.

38. Van den Bulck J, Van Mierlo J. Energy intake associated with television viewing in adolescents, a cross sectional study. Appetite. 2004;43(2):181-184.

39. Scully M, Dixon H, Wakefield M. Association between commercial television exposure and fast-food consumption among adults. Public Health Nutr. 2009;12(1):105-110.

40. Hendrie G, Noakes M. Fruit, vegetables and diet score. Canberra: CSIRO; 2017.

41. Wilson LF, Antonsson A, Green AC, et al. How many cancer cases and deaths are potentially preventable? Estimates for Australia in 2013. Int J Cancer. 2018;142(4):691-701.

42. Lee MK, Amorin-Woods L, Cascioli V, Adams J. The use of nutritional guidance within chiropractic patient management: a survey of 333 chiropractors from the ACORN practice-based research network. Chiropr Man Therap. 2018;26(1):7.

43. Jamison J. Health information and promotion in chiropractic clinics. J Manipulative Physiol Ther. 2002;25(4):240-245.

44. Holtzman D, Burke J. Nutritional counseling in the chiropractic practice: a survey of New York practitioners. J Chiropr Med. 2007;6(1):27-31.

45. Paavola M, Vartiainen E, Haukkala A. Smoking, alcohol use, and physical activity: a 13-year longitudinal study ranging from adolescence into adulthood. J Adolesc Health. 2004;35(3):238-244

46. Wang D, Wang Y, Wang Y, Li R, Zhou C. Impact of physical exercise on substance use disorders: a meta-analysis. PLoS One. 2014;9(10):e110728.
47. Roessler KK. Exercise treatment for drug abuse-a Danish pilot study. Scand J Public Health. 2010;38(6):664-669.

48. Buchowski MS, Meade NN, Charboneau E, et al. Aerobic exercise training reduces cannabis craving and use in non-treatment seeking cannabis-dependent adults. PLoS One. 2011;6(3): 17465

49. Hoskins W, Pollard H, Garbutt P. How to select a chiropractor for the management of athletic conditions. Chiropr Osteopat. 2009;17(1):3.

50. Adams J, Lauche R, de Luca K, Swain M, Peng W, Sibbritt D. Prevalence and profile of Australian chiropractors treating athletes or sports people: a cross-sectional study. Complement Ther Med. 2018;39:56-61.

51. Finch C, Cassell E. The public health impact of injury during sport and active recreation. J Sci Med Sport. 2006;9(6):490-497.

52. van Mechelen W, Hlobil H, Kemper HCG. Incidence, severity, aetiology and prevention of sports injuries. Sports Med. 1992;14(2):82-99.

53. Shane ER, Pierce KM, Gonzalez JK, Campbell NJ. Sports chiropractic management of concussions using the Sport Concussion Assessment Tool 2 symptom scoring, serial examinations, and graded return to play protocol: a retrospective case series. $J$ Chiropr Med. 2013;12(4):252-259.

54. Gabbett TJ. The training-injury prevention paradox: should athletes be training smarter and harder? Br J Sports Med. 2016 bjsports-2015-095788.

55. List M, Nolz Z, Nord W, Huntington M. Return-to-play: a primary care physician's guide to management. S D J Med. 2015;68(3) 121-3, 5.

56. Lauersen JB, Bertelsen DM, Andersen LB. The effectiveness of exercise interventions to prevent sports injuries: a systematic review and meta-analysis of randomised controlled trials. Br J Sports Med. 2013 bjsports-2013-092538.

57. Julian C, Hoskins W, Vitiello AL. Sports chiropractic management at the World Ice Hockey Championships. Chiropr Osteopat. 2010;18(1):32.

58. Pribicevic M, Pollard H. A multi-modal treatment approach for the shoulder: a 4 patient case series. Chiropr Osteopat. 2005;13(1):20.

59. de Luca KE, Gliedt JA, Fernandez M, Kawchuk G, Swain MS. The identity, role, setting, and future of chiropractic practice: a survey of Australian and New Zealand chiropractic students. J Chiropr Educ. 2018;32(2):115-125.

60. Lowe A, Littlewood C, McLean S, Kilner K. Physiotherapy and physical activity: a cross-sectional survey exploring physical activity promotion, knowledge of physical activity guidelines and the physical activity habits of UK physiotherapists. BMJ Open Sport Exerc Med. 2017;3(1):e000290. 